\title{
Physicians' propensity to offer genetic testing for Alzheimer's disease: Results from a survey
}

Gary A. Chase, PhD ${ }^{1}$, Gail Geller, PhD ${ }^{2,3}$, Suzanne L. Havstad, $M A^{1}$, Neil A. Holtzman, $M D^{3}$, and Susan Spear Bassett, $\mathrm{PhD}^{4}$

\begin{abstract}
Purpose: Examine physician knowledge, preferences, and use of genetic tests for Alzheimer's disease (AD).
Methods: Survey of 426 community-based physicians treating AD patients. Results: Majority gave inaccurate estimates of AD risk. Medical specialty predicted appropriate use of current tests. Recommending substances to prevent memory loss was related to acceptance of error-free tests. High patient loads and familiarity with genetic tests predicted lower tolerance for test error. Conclusion: Physicians do not endorse indiscriminate genetic susceptibility testing for AD. However, insufficient knowledge of disease risk, etiology, genetic susceptibility, and use of existing tests indicated a need for further physician education in this area. Genet Med 2002:4(4):297-303.
\end{abstract}

Key Words: Alzheimer's disease, genetic testing, physician survey, genetics

Alzheimer's disease (AD) is one of the most common threats to the elderly with a risk of approximately $12 \%$ to $15 \%$ that a 65-year-old would become affected during his or her remaining lifetime; this risk is steeply concentrated toward the end of the lifespan. ${ }^{1-7}$ Familial aggregation of disease alters the lifetime risk, with the presence of an affected first-degree relative producing a two- to threefold increase in risk. ${ }^{8-13}$

Initial efforts to understand the role of genetics in $\mathrm{AD}$ focused on extremely rare, multigenerational families where disease onset occurs in the fourth or fifth decade of life (earlyonset AD). These autosomal dominant forms of the disease account for no more than $5 \%$ to $10 \%$ of all $\mathrm{AD}$ cases. At present, three gene loci are linked to early-onset $\mathrm{AD},{ }^{14-16}$ with the presenilin 1 gene on chromosome 14 appearing to be the major early-onset locus. ${ }^{16}$ Mutations of these three genes are virtually $100 \%$ penetrant in the approximately 100 families studied thus far and explain approximately half of the earlyonset cases. ${ }^{17}$

In the vast majority of $\mathrm{AD}$ cases, in which disease onset occurs after the age of 65, only the APOE gene located on chromosome 19 has been shown to be associated with increased disease risk, with a significantly higher frequency of the $\epsilon 4$ allele found in cases compared with controls. ${ }^{18-21}$ Although the presence of one $\epsilon 4$ allele appears to double the risk of AD at age $65,{ }^{1,22,23}$ a substantial proportion of $\epsilon 4$-positive persons never experience the onset of AD. In addition, it appears that From the ${ }^{1}$ Department of Biostatistics and Research Epidemiology, Henry Ford Health Sci-
ences Center; and ${ }^{2}$ the Bioethics Institute, ${ }^{3}$ the Institute of Genetic Medicine, and the ${ }^{4}$ De-
partment of Psychiatry and Behavioral Sciences, Johns Hopkins University School of Medi-
cine, Baltimore, Maryland.

Susan S. Bassett, PhD, Johns Hopkins Hospital, Osler 320, 600 North Wolfe Street, Baltimore, MD 21287-5371.

Received: January 30, 2002.

Accepted: March 25, 2002.

DOI: 10.1097/01.GIM.0000020817.40341.DD roughly $35 \%$ to $50 \%$ of those suffering from $\mathrm{AD}$ do not have the $\epsilon 4$ allele, that the frequency of this allele may be similar in other dementing conditions, and that the association of $\epsilon 4$ with $\mathrm{AD}$ may vary with ethnic background, ${ }^{24-26}$ prompting medical geneticists and others to recommend against the use of APOE genotyping for prediction of risk in asymptomatic individuals. ${ }^{24,27}$

Continuing advances in molecular genetics will identify other genes that may play a role in $\mathrm{AD}$, further increasing the expectations of the public regarding the predictive accuracy of genetic susceptibility tests and the prospects for effective intervention. Studies indicate the majority of physicians have insufficient training for the understanding of genetic probabilities, penetrance, the notion of competing risk or calculation of positive predictive value. ${ }^{28,29} \mathrm{~A}$ survey of 50 physicians found less than half had accurate knowledge of the baseline risk of $\mathrm{AD}$ and $<5 \%$ understood the alteration in risk associated with the presence of the $\epsilon 4$ allele. ${ }^{1}$ At the present time, genetic testing for the APOE gene as well as the PS1 gene is available and being marketed directly to physicians for use in appropriate circumstances as defined by the manufacturer. ${ }^{30}$ Effective physician patient communication may be hampered by two factors: physician uncertainty regarding the meaning of predictive test results, and physician inability to identify situations for which testing is clearly inappropriate. ${ }^{29}$

This study was undertaken to survey the attitudes and knowledge of physicians regarding probable causes and risk of $\mathrm{AD}$, as well as their propensity to offer genetic testing, both in real testing situations involving the offer of $P S 1$ and $A P O E$ and hypothetical scenarios for which only the error rates of the test are to be considered.

\section{SUBJECTS AND METHODS}

The physicians included in this study, identified through family informants and medical record review, had evaluated or 
treated AD patients enrolled in a genetic linkage study of 165 primarily late-onset families with two or more affected siblings. A total of 520 physicians were initially identified, of which 426 were living and could be located. All were invited to participate, and 171 (40\%) responded. These physicians had not previously participated in our ongoing studies. The study was approved for expedited review by the Institutional Review Board, and consent was suggested with return of the survey. The survey was designed as part of a long-term research effort that assesses both physician and patient responses to a number of genetic testing situations. Portions of the questionnaire stemmed from this earlier work. ${ }^{31,32}$ The survey was drafted and reviewed by a group which included genetic testing researchers, psychiatrists experienced in Alzheimer's disease treatment, and physicians representing several specialties in a leading university hospital. It was then pilot tested on several university-based physicians who cared regularly for $\mathrm{AD}$ patients.

The survey was mailed with a cover letter describing the study, indicating intent, and ensuring confidentiality. The package included an incentive check for $\$ 10$, as previous work has shown that even small monetary incentives significantly increase physician response rates, ${ }^{33}$ and a stamped self-addressed return envelope. Reminder postcards were mailed 3 weeks after the initial mailing.

The survey included, but was not limited to, the following domains:

\section{Physician attributes}

These included age, gender, year of residency completion, specialty certification, religious background, influence of religion on decision-making, marital status, and whether $\mathrm{AD}$ was present in a parent, grandparent, sibling, spouse, or other relative.

\section{Practice characteristics}

Physicians were queried regarding their practice setting, approximate number of total patients under their care, the proportion who reside in nursing homes, experience with $\mathrm{AD}$ patients, and their recommendation of drugs or other substances for the possible prevention of memory loss.

\section{Endorsement of causal factors}

Physicians were asked to indicate their agreement or disagreement with a list of 13 separate causal factors for $\mathrm{AD}$ including chance and inheritance of specific genes.

\section{Knowledge of AD risk}

Physicians were asked to supply their estimate of the population risk for $\mathrm{AD}$, the change in risk associated with the presence of an affected parent, and the change in risk associated with a positive test for APOE or PS1.

\section{Use of currently available AD genetic tests}

Physicians were presented with five questions to gauge their familiarity with both the APOE and PS1 tests. A Likert-type scale was constructed from these items for each test, creating familiarity dimensions with Cronbach's alpha (PS1, 0.6478; $A P O E, 0.7174)$ and subsequently dichotomized for use in multiple regression models. In addition, they were presented clinical histories and asked to indicate how likely they would be to offer the APOE and PS1 test to these individuals.

\section{Projected offering of hypothetical genetic tests}

Physicians were asked to indicate the minimum positive predictive value (the proportion of patients testing positive who actually develop the disease, PPV) that a genetic test for $\mathrm{AD}$ should achieve in order for that test to be offered in practice. They were then presented with questions portraying a range of genetic testing situations (e.g., a perfect test, tests with varying degrees of false negatives, and tests with varying degrees of false positives) and asked whether they would or would not offer the test to their patients.

\section{RESULTS}

\section{Physician characteristics, attitudes, and beliefs about AD}

The 171 physicians who completed the survey (40\% of the sample) had a mean age of 51.7 years $(\mathrm{SD}=10.0)$, were largely male $(90.0 \%)$ and married (89.4\%). Thirty-seven percent indicated that a relative was affected with $\mathrm{AD}$. Their religious background was predominantly Judeo-Christian (35.3\% Protestant, $25.9 \%$ Jewish, $24.0 \%$ Catholic) and 65\% indicated that when making major decisions, they were either somewhat or very influenced by values associated with their religion.

Physicians represented general internists $(32 \%)$, family practitioners (30\%), neurologists (18\%), psychiatrists (11\%), geriatricians $(5 \%)$, and other specialties (4\%). Seventy-eight percent of the physicians saw their patients in a solo or private group practice; only $3 \%$ reported an HMO as their primary practice setting. Sixty-six percent of the doctors reported a practice size of 1,000 or more patients, with an overall median of 2,000. Within their practices, physicians recommended a number of substances for the possible prevention of memory loss, including Aricept (74.3\%), estrogen (60.2\%), vitamin E (59.6\%), ginkgo (34.5\%), Cognex (27.5\%), nonsteroidal antiinflammatory medications (24.6\%), and vitamin C (18.7\%).

All physicians in the study cared for patients with $\mathrm{AD}$, with $51.6 \%$ reporting more than $25 \mathrm{AD}$ patients currently under care. In addition, the responding physicians saw over three quarters of those patients with $\mathrm{AD}$ at least twice a year. Physicians were presented with a list of possible causes of $\mathrm{AD}$ and were asked to rate their level of agreement on a 4-point scale with the two upper values indicating agreement. Inheriting specific genes was the most highly endorsed causal factor followed by aging and then chance, strokes, and hardening of the arteries (Table 1).

\section{Estimation of risk}

Doctors were asked to estimate the chance of an asymptomatic 65-year-old developing $\mathrm{AD}$ over their lifetime, in two cases, one for whom there was no history of an affected parent 
Table 1

Physician endorsement of possible causal factors for the development of AD

\begin{tabular}{lcc}
\hline Possible causal factor & \% Agree & \% Disagree \\
\hline Exposure to aluminum & 9.7 & 90.3 \\
Chance & 45.8 & 54.2 \\
Inheriting specific genes & 95.3 & 4.7 \\
Poisons in air/water supply & 8.4 & 91.6 \\
God's will & 15.1 & 84.9 \\
Aging & 72.2 & 27.8 \\
Poor diet & 12.0 & 88.0 \\
Not being mentally active & 40.1 & 59.9 \\
Hardening of arteries & 42.5 & 57.5 \\
Strokes & 45.5 & 54.5 \\
Hormone levels & 28.9 & 71.1 \\
Drinking too much alcohol & 30.1 & 69.9 \\
Injuries to the head & 38.9 & 61.1 \\
\hline
\end{tabular}

and the other for whom there was one affected parent. Table 2 presents the grouped risk estimates, using the same categories as Seshadri and colleagues for comparison. As can be seen, less than half of the physicians placed the risk estimate for those without an affected parent correctly, that is, between $11 \%$ and $20 \%$ (although the question is framed to reflect risk after the age 65, use of lifetime risk estimates as a standard is appropriate because virtually all the cases occur after the age of 65 ). Of those who were incorrect, the majority underestimated the risk. In the case for which there was a parent affected with $\mathrm{AD}$, again slightly less than half of the physicians placed their estimate in the correct range. Other responses were evenly divided between overestimation and underestimation. Cross-tabulating these estimates, however, revealed only $35 \%$ of physicians providing estimates in the correct ranges for both conditions. A comparison of physicians with correct risk estimates and those with incorrect risk estimates failed to uncover any differences with respect to age, years since residency, specialty, familiarity with $A P O E$ or $P S 1$, the number of $\mathrm{AD}$ patients treated, or the presence in their own family of a relative affected with $\mathrm{AD}$.

Table 2

Estimates of lifetime risk for developing $\mathrm{AD}$ among 65 -year-olds by status of parent

\begin{tabular}{lcc}
\hline Risk estimate & $\begin{array}{c}\text { Without affected } \\
\text { parent }\end{array}$ & $\begin{array}{c}\text { With affected } \\
\text { parent }\end{array}$ \\
\hline $0 \%-10 \%$ & 35.3 & 3.5 \\
$11 \%-20 \%$ & $48.2^{a}$ & 20.0 \\
$21 \%-40 \%$ & 8.8 & $48.2^{a}$ \\
$>40 \%$ & 7.6 & 28.2 \\
\hline
\end{tabular}

Values represent proportion of sample.

${ }^{a}$ Correct answer.

\section{Use of currently available genetic tests}

Physicians were informed that clinical laboratory testing was currently available for two genes associated with $\mathrm{AD}$ (APOE and PS1) and were queried specifically about their familiarity with these tests. Sixty-five percent of the respondents $(N=110)$ had heard of $A P O E, 33 \%$ had received literature about the test, and $18 \%$ had ordered at least one APOE test for a patient. In addition, $15.5 \%$ of physicians reported that an asymptomatic patient had requested $A P O E$ testing, and 5.3\% had ordered at least one $A P O E$ test for an asymptomatic individual. Physicians who had heard about $A P O E(N=110)$ estimated the risk for a person with a positive $A P O E$ test (PPV) to range from $8 \%$ to $95 \%$, with a mean of $47.3 \%$ ( $S D=20.4 \%$ ).

A smaller subset of 61 physicians (37\%) had also heard of PS1, 13\% had received literature about the test, and 5\% had ordered the test for a patient under evaluation. In addition, $4 \%$ had an asymptomatic patient ask for the test and 3\% had ordered the PS1 test for an asymptomatic relative of a patient with $\mathrm{AD}$. For those physicians who indicated they had heard of PS1 $(N=61)$, their estimated risk (PPV) that a person with a positive $P S 1$ test would develop AD ranged from $20 \%$ to $100 \%$, with a mean of $53.5 \%(S D=23.6 \%)$.

To examine physicians' understanding of the appropriateness of their use, respondents were asked to indicate how likely they would be to offer the APOE and PS1 tests to individuals of varying clinical histories. The responses are presented in Table 3. Among the 110 physicians who had heard of the APOE test, over $90 \%$ indicated they would be unlikely to use the test for presymptomatic testing (Question 1). However, when it came to use of the test for diagnostic purposes (Questions 2 and 3), physicians seemed less sure of its correct use. A multiple logistic regression model was used to identify predictors of correct use for the situation described in Question 3, where use of the $A P O E$ test would be considered inappropriate; therefore, affirmative responses to this question are considered incorrect. Variables entered into the model included: estimate of positive predictive value for $A P O E$ test, knowledge of $A D$ risk, number of $\mathrm{AD}$ patients treated yearly, propensity to recommend medications and other treatments for memory loss, medical specialty, recency of training, importance of religious values on decision-making, and belief in chance as a probable cause of AD. Only specialty proved to be significantly related to a correct response, with $53 \%$ of the neurologists and psychiatrists providing correct responses compared with $32 \%$ among other physicians $\left(\chi^{2}=4.22 ; P<0.05\right)$.

A second set of three questions pertained to PS1 testing and responses for the 61 physicians who indicated they had heard of this test were analyzed. Among the smaller subset of physicians who indicated they had heard of the PS1 test, the most likely case for its use was to assist with diagnosis of a young symptomatic patient. These physicians were only half as likely to offer this test for presymptomatic testing. Question 3 presents a case for which use of the PS1 test is not appropriate; therefore, affirmative responses to this question are considered 
Table 3

Physicians' stated propensity to order APOE and PS1 testing

\begin{tabular}{|c|c|c|c|}
\hline & $\begin{array}{l}\text { Likely } \\
(\%)\end{array}$ & $\begin{array}{l}\text { Unlikely } \\
(\%)\end{array}$ & Appropriate \\
\hline \multicolumn{4}{|l|}{ When considering the APOE test how likely would you be to: } \\
\hline $\begin{array}{l}\text { 1. Offer the APOE test to an asymptomatic individual over the age } \\
\text { of } 65 \text {, with no family history of AD? }\end{array}$ & 9.4 & 90.6 & No \\
\hline $\begin{array}{l}\text { 2. Offer the APOE test to a symptomatic individual over the age of } \\
65 \text { currently being evaluated for memory problems? }\end{array}$ & 47.2 & 52.8 & Yes \\
\hline $\begin{array}{l}\text { 3. Offer the APOE test to a symptomatic individual under the age } \\
\text { of } 50 \text { from a family with many cases of early AD? }\end{array}$ & 58.5 & 41.5 & No \\
\hline \multicolumn{4}{|l|}{ When considering the Presenilin 1 test how likely would you be to: } \\
\hline $\begin{array}{l}\text { 1. Offer the PS1 test to an asymptomatic individual under the age } \\
\text { of } 50 \text { in a family with many cases of early AD? }\end{array}$ & 39.3 & 60.7 & Yes \\
\hline $\begin{array}{l}\text { 2. Offer the PS1 test to a symptomatic individual under the age of } \\
50 \text { from a family with many cases of early AD? }\end{array}$ & 66.0 & 34.0 & Yes \\
\hline $\begin{array}{l}\text { 3. Offer the PS1 test to a symptomatic individual between the ages } \\
\text { of } 50 \text { and } 65 \text { with no family history of early onset AD? }\end{array}$ & 32.1 & 67.9 & No \\
\hline
\end{tabular}

Tabulation is limited to respondents who had heard of the specific test.

incorrect. Examination of predictors for responses to this question included: estimate of positive predictive value for PS1 test, knowledge of $\mathrm{AD}$ risk, propensity to recommend medications and other treatments for memory loss, medical specialty, recency of training, importance of religious values on decisionmaking, and belief in chance as a probable cause of AD. As in the previous situation, the only significant predictor of a correct response was specialty training in psychiatry/neurology $\left(\chi^{2}=6.88 ; P<0.01\right) ; 83 \%$ of psychiatrists and neurologists answered correctly compared with $46 \%$ of other physicians.

\section{Propensity to offer genetic tests with varying error rates}

The physicians were asked to indicate the minimum level of PPV they believed should be achieved by a genetic test for Alzheimer's disease in order for that test to be offered in clinical practice. Responses ranged from $20 \%$ to $100 \%$, with the median response $80 \%$. Stepwise multiple regression was used to investigate the association of a number of characteristics with PPV. Physician responses were not correlated with recency of training, medical specialty, propensity to recommend medications and other treatments for memory loss, knowledge of AD risk, familiarity with PS1 or APOE tests, belief in chance as a probable cause of $\mathrm{AD}$ or importance of religious values in decision-making. There was, however, a significant association between physician interest in higher PPV for a genetic test for $\mathrm{AD}$ and the evaluation and treatment of more than $25 \mathrm{AD}$ patients yearly by the physician ( 68.7 vs. $79.1 ; \mathrm{F}=12.94, P<$ 0.001 ).

Subsequently physicians were asked about a range of predictive values applicable in their own practice with the use of vignettes. Physicians were told it was likely that, in the future, genetic tests would be developed for the purpose of identifying inherited factors that increase the risk of AD. Such tests involve uncertainty, and there may be false negatives (where the test fails to detect some people who will eventually develop AD), producing a test with $<100 \%$ sensitivity, or the ability to detect all cases. There may also be false positives (where the test incorrectly classifies as a case individuals who will remain disease free) producing a test with $<100 \%$ positive predictive value. Physicians were asked to assume that the test would be painless, inexpensive, and totally confidential. The vignettes were based on testing a group of 100 individuals, 13 of who would eventually develop $\mathrm{AD}$ and 87 of whom would not. In each case, physicians were asked if they would offer the test to their patients. The physician responses are shown in Table 4.

As can be seen from inspection of this table, approximately $84 \%$ of physicians would offer an error-free genetic test for $\mathrm{AD}$ to their patients. This percentage declined with increasing error rates, with the provision of false-positive results inhibiting propensity to offer the test more significantly than the provision of false-negative results.

We performed several multivariate logistic regression models with willingness to offer (1) a perfect test and (2) a test with 87\% PPV (Question 5) as dichotomous outcomes. The test with $87 \%$ PPV, endorsed by $45 \%$ of respondents, was chosen because the proportion of respondents willing to offer the next best PPV $(65 \%)$ dropped steeply to $<15 \%$. Predictor variables explored included time since residency, specialty board certification in psychiatry/neurology, familiarity with $A P O E$ and PS1 testing, propensity to recommend medications and other treatments for memory loss, number of $\mathrm{AD}$ patients treated yearly, estimation of lifetime risk for $\mathrm{AD}$, belief in chance as a probable cause of $\mathrm{AD}$, and importance of religious values in decision-making.

Willingness to offer a test with $100 \%$ positive predictive value (PPV) and no false negatives (a perfect test) proved to be related to a physician's propensity to recommend substances for possible prevention of memory loss and increased impor- 
Table 4

Physicians' willingness to offer genetic tests of varying error rates to their patients

Offer test to your patients?

Vignette

Yes No

Vignette 1

1. Suppose a perfect test becomes available. That is, in the group of 100 individuals being tested, the 13 people who test positive go on to develop AD and the 87 people who test negative never develop AD. $(\mathrm{PPV}=100 \%$; Sensitivity $=100 \%)$

In Vignettes 2-4, the test always assigns a negative result to the 87 people who will not develop $\mathrm{AD}$, but a percentage of individuals who will develop AD go undetected. (PPV $=100 \%$; Sensitivity $91 \%-31 \%$ )

2. Test correctly identifies $12 / 13$ who will develop AD

3. Test correctly identifies $9 / 13$ who will develop $A D$

In Vignettes 5-7, the test always assigns a positive result to all 13 individuals who will develop AD; however, a percentage of the individuals who will not develop AD are misclassified. (PPV 87\%-33\%; Sensitivity $=100 \%$ )

5. Test gives incorrect positive results to $2 / 87$ who will not develop $\mathrm{AD}$

6. Test gives incorrect positive results to $7 / 87$ who will not develop $\mathrm{AD}$

tance of religious values in decision-making. Those recommending more antidementia treatments had a higher probability of offering a perfect test $\left(91 \%\right.$ vs. $78 \% ; \chi^{2}=4.80 ; P<$ 0.03 ). There was a steadily increasing trend for willingness to offer the perfect test as role of religious values in decisionmaking increased (low, $75 \%$; medium, $83 \%$; high, $93 \%$; $\chi^{2}$ for trend $=6.23 ; \mathrm{df}=1 ; P=0.013)$.

For offering the test with $87 \% \mathrm{PPV}$, familiarity with $A P O E$ testing was the only significant predictor, with an inverse relationship between familiarity and offering this test. The $53 \%$ of physicians with less familiarity with $A P O E$ testing would offer their patients a genetic test for AD with an $87 \% \mathrm{PPV}$, whereas only $36 \%$ of those physicians with greater exposure to APOE testing would offer such a test $\left(\chi^{2}=4.41 ; P<0.04\right)$. Notably there was no significant relationship between a physician's willingness to offer the $87 \%$ PPV test and the minimum level of positive predictive value they had earlier indicated should be achieved for a genetic test for $\mathrm{AD}$ for that test to be offered in practice. As reported above, the median positive predictive value for an acceptable test was $80 \%$. This median acceptable PPV was nearly identical for those who would and would not offer the $87 \%$ PPV test.

\section{DISCUSSION}

As genetic susceptibility testing moves into clinical practice, physicians' understanding of susceptibility tests and the attendant recommendation and use of them becomes extremely important. Our findings indicate that a clear majority (65\%) of physician respondents were familiar with $A P O E$ testing and unlikely to offer this test for asymptomatic individuals, in line with the current scientific and clinical recommendations. ${ }^{24,27,34}$ Although fewer physicians were knowledgeable about the PS1 test, the majority were also unlikely to use this test for presymptomatic testing. Even in cases where use of these tests would be indicated, no more than two thirds of physicians would likely order them; this finding suggests caution rather than overenthusiasm.

The survey does highlight several areas of concern, however. Physicians were asked to assess the conditional risk for an unaffected person aged 65 to become affected with Alzheimer's disease at some future time. Actuarially this is equivalent to requesting an estimate of the conditional lifetime risk, which adjusts for the failure to become affected before 65 . Because the vast majority of $\mathrm{AD}$ cases do not manifest under the age of 65 , the correct answer is approximately the same as the unconditional lifetime risk. Although most physicians are probably unfamiliar with the technical refinements of actuarial estimation, it is reasonable to expect them to know the approximate probability to become affected for a condition with such high frequency in the elderly. However, as in the earlier report by Seshadri et al., ${ }^{1}$ less than half of the physicians surveyed knew either the lifetime risk of $\mathrm{AD}$ or the change in risk when there is an affected parent; they generally underestimated the true risk. In addition, the endorsement of hardening of the arteries, strokes, and alcoholism as probable causes of AD by a third of physicians, suggests some difficulty discriminating $\mathrm{AD}$ from other types of dementia. Lack of knowledge regarding disease risk and etiology will likely impact physician recommendations for genetic testing.

Furthermore, physician estimates of risk, given a positive APOE or PS1 test, were very similar, despite the contrasting implications of a positive finding in these two situations. Finally, there was the nontrivial rate at which physicians used $A P O E$ testing in asymptomatic individuals, possibly in response to patient demand. Almost one sixth of respondents had been asked to order this test under circumstances in which 
testing is not recommended, and of these, nearly one third had indeed done this.

Concerns have been expressed that lack of knowledge, interest, or time on the part of physicians could compromise the introduction of $\mathrm{AD}$ genetic testing into clinical practice. In one of their first studies, a survey of 1,795 physicians in 10 states, Hofman and colleagues found that many nongeneticists showed decreased awareness and knowledge of genetics and genetic tests when compared with a standard based on genetically trained clinical personnel. ${ }^{28}$ Our results indicate that among physicians who care for patients with $\mathrm{AD}$, the majority are familiar with $A P O E$ testing and appropriately cautious about using this test. However, many fewer physicians are aware of PS1 testing, and some respondents underestimated its definitiveness. The possible overuse of APOE testing, e.g., in asymptomatic persons, could result more from patient demand than from lack of knowledge by providers, although both factors may contribute to the problem.

The physicians surveyed, primarily middle-aged males in private practice, had substantial experience with the evaluation and treatment of $\mathrm{AD}$ patients in practice settings where risk to offspring and younger sibs would clearly emerge in many families. Although over $80 \%$ of these physicians would offer a perfect genetic test for $\mathrm{AD}$, e.g., to confirm a clinical diagnosis or for a relative eager to know the future, there was little interest in genetic susceptibility testing when error rates climbed above the $20 \%$ margin. In fact, once hypothetical genetic tests for $\mathrm{AD}$ introduced error, physicians familiar with current genetic testing were more hesitant than their less-familiar colleagues to offer such a test. Physicians appear sensitive to the import of $\mathrm{AD}$ test results for their patients, being much less willing to offer tests that produce false-positive results. The majority of physicians were unwilling to offer a test with even a $2 \%$ falsepositive rate, likely reflecting the absence of effective treatment for this condition.

Our findings revealed internal inconsistency regarding physicians' criteria for an acceptable error rate, perhaps raising a note of caution in the interpretation of these results. Physicians indicated that genetic tests for $\mathrm{AD}$ should have a minimum positive predictive value of $80 \%$ to be offered in clinical practice. However, this threshold was unrelated to physician interest in offering their patients a test with an $87 \%$ positive predictive value, a test which exceeds that threshold. The failure to find the expected association between these two suggests either that the pattern of responses reflects a distinction between a hypothetical or abstract opinion and contemplation of a professional course of action, or that the particular framing of the questions played a role in physician response.

Finally, it should be noted that even with the use of monetary incentives and repeated follow-up, less than half the physicians responded, perhaps limiting these findings, although it is not clear that increased response rates would necessarily alter our study findings. ${ }^{32}$ Although it is only a speculative point, a response bias favoring physicians with greater interest in or knowledge of genetic testing would suggest that these findings may overestimate the current level of knowledge regarding genetics and $\mathrm{AD}$ among practicing physicians.

In summary, our results contain grounds for both optimism and pessimism regarding the future utilization of AD genetic susceptibility testing in clinical practice. Physicians do not appear to endorse widespread genetic testing under inappropriate conditions. Error rates larger than $20 \%$ were a strong discouraging factor, indicating the importance of accuracy to the clinician for such a grave prognosis. However, knowledge of disease risk and causal factors related to $\mathrm{AD}$, as well as familiarity with well-known genetic etiologies, were less than satisfactory. Because at any one time there will be wide variation in knowledge of and readiness to offer these tests, our findings highlight the importance of creating new mechanisms for rapid diffusion of genetic testing information relevant to clinical practice.

\section{Acknowledgment}

This research was supported by RO1-HG01655, National Human Genome Research Institute, to Dr. Bassett.

\section{References}

1. Seshadri S, Drachman DA, Lippa CF. Apolipoprotein E e4 allele and the lifetime risk of Alzheimer's disease. Arch Neurol 1995;52:1074-1079.

2. Bachman DL, Wolf PA, Linn R, Knoefel JE, Cobb J, Belanger A, D'Agostino RB, White LR. Prevalence of dementia and probable senile dementia of the Alzheimer type in the Framingham Study. Neurology 1992;42:115-119.

3. Bachman DL, Wolf PA, Linn R, Knoefel JE, Cobb JL, Belanger AJ, White LR, D'Agostino RB. Incidence of dementia and probable Alzheimer's disease in the general population: The Framingham Study. Neurology 1993;43:515-519.

4. Evans DA, Funkenstein HH, Albert MS, Scherr PA, Cook NR, Chown MJ, Hebert LE, Hennekens CH, Taylor JO. Prevalence of Alzheimer's disease in a community population of older persons: higher than previously reported. JAMA 1989;262:25512556.

5. Hebert LE, Scherr PA, Beckett LA, Albert MS, Pilgrim DM, Chown MJ, Funkenstein $\mathrm{HH}$, Evans DA. Age-specific incidence of Alzheimer's disease in a community population. JAMA 1995;273:1354-1359.

6. Kokmen E, Beard CM, O'Brien PC, Offord MS, Kurland,LT. Is the incidence of dementing illness changing? A 25-year time trend study in Rochester, Minnesota (1960-1984). Neurology 1993;43:1887-1892.

7. Letenneur L, Commenges D, Dartigues JF, Berbeger-Gateau P. Incidence of dementia and Alzheimer's disease in elderly community residents of Southwestern France. Int J Epidemiol 1994;23:1256-1261.

8. Rocca WA. Frequency, distribution, and risk factors for Alzheimer's disease. Nursing Clin North Am 1994;29:101-111.

9. Huff FJ, Auerbach J, Chakravarti A, Boller F. Risk of dementia in relatives of patients with Alzheimer's disease. Neurology 1988;38:786-790.

10. Lautenschlager NT, Cupples LA, Rao VS, Auerbach SA, Becker R, Burke J, Chui H, Duara R, Foley EJ, Glatt SL, Green RC, Jones R, Karlinsky H, Kukull WA, Kurz A, Larson EB, Martelli K, Sadovnick AD, Volicer L, Waring SC, Growdon JH, Farrer LA. Risk of dementia among relatives of Alzheimer's disease patients in the MIRAGE study: What is in store for the oldest old? Neurology 1996;46:641-650.

11. Farrer LA, O'Sullivan DM, Cupples LA, Growdon JH, Myers RH. Assessment of genetic risk for Alzheimer's disease among first-degree relatives. Ann Neurol 1989; 25:485-493.

12. Li G, Silverman JM, Smith CJ, Zaccario ML, Schmeidler J, Mohs RC, Davis KL. Age at onset and familial risk in Alzheimer's disease. Am J Psychiatry 1995;152:424-430.

13. The Canadian Study of Health and Aging. Risk factors for Alzheimer's disease in Canada. Neurology 1994;44:2073-2080.

14. Goate AM, Haynes AR, Owen MJ, Farrall M, James LA, Lai LY, Mullan MJ, Roques P, Rossor MN, Williamson R. Predisposing locus for Alzheimer's disease on chromosome 21. Lancet 1989;18:352-355.

15. Levy-Lahad E, Wasco W, Poorkaj P, Romano DM, Oshima J, Pettingell WH, Yu CE, Jondro PD, Schmidt SD, Wang K. Candidate gene for the chromosome 1 familial Alzheimer's disease locus. Science 1995;269:973-977. 
16. Schellenberg GD, Bird TD, Wijsman EM, Orr HT, Anderson L, Nemens E, White JA, Bonnycastle L, Weber JL, Alonso ME. Genetic linkage evidence for a familial Alzheimer's disease locus on chromosome 14. Science 1992;258:668-671.

17. St. George-Hyslop PH. Molecular genetics of Alzheimer's disease. Biol Psychiatry 2000;47:183-199.

18. Selkoe DJ. Alzheimer's disease: genes, proteins, and therapy. Psychol Rev 2001;81: 741-766.

19. Strittmatter WJ, Saunders AM, Schnechel D, Pericak-Vance M, Enghild J, Salvesen GS, Roses AD. Apolipoprotein E: High avidity binding to Beta-amyloid and increased frequency of type 4 allele in late-onset familial Alzheimer disease. Proc Nat Acad Sci U S A 1993;90:1977-1981.

20. Saunders AM, Strittmatter WJ, Schmechel D, George-Hyslop PH, Pericak-Vance MA, Joo SH, Rosi BL, Gusella JF, Crapper-MacLachlan DR, Alberts MJ. Association of apolipoprotein E allele Epsilon 4 with late-onset familial and sporadic Alzheimer's disease. Neurology 1993;43:1467-1472.

21. Roses AD, Saunders AM. APOE is a major susceptibility gene for Alzheimer's disease. Curr Opin Biotechnol 1994;5:663-667.

22. Holtzman NA. Benefits and risks of emerging genetic technologies: the need for regulation. Clin Chem 1994;40:1652-1657.

23. Farrer LA, Cupples LA, Haines JL, Hyman B, Kukull WA, Mayeux R, Myers RH, Pericak-Vance MA, Risch N, van Dujin CM. Effects of age, sex, and ethnicity on the association between Apolipoprotein E genotype and Alzheimer disease. JAMA 1997; 278:1349-1356.

24. ACMG/ASHG Working Group. Statement on use of apolipoprotein E testing for Alzheimer's disease. JAMA 1995;274:1627-1629.

25. Slooter AJC, Breteler MMB, Ott A, VanBroeckhoven C, van Duijn CM. APOE genotyping in differential diagnosis of Alzheimer's disease. Lancet 1996;348:334.
26. Thilmann P, Ernst C, Czech C, Kaumeier S, Beyreuther K, Förstl H. Low apolipoprotein E4 allelic frequency in Alzheimer's disease and functional psychiatric disorders. Dementia 1996;7:118-119.

27. National Institute on Aging/Alzheimer's Association Working Group. Apolipoprotein E genotyping in Alzheimer's disease. Lancet. 1996;347:1091-1095.

28. Hofman KA, Tambor ES, Chase GA, Faden RR, Holtzman NA. Physicians' knowledge of genetics and genetic tests. Acad Med 1993;68:625-632.

29. James CA, Geller G, Bernhardt BA, Doksum T, Holtzman NA. Are practicing and future physicians prepared to obtain informed consent? The case of genetic testing for susceptibility to breast cancer. Community Genet 1998;1:203-212.

30. Tobin SL, Chun N, Powell TM, McConnell LM. The genetics of Alzheimer disease and the application of molecular tests. Genet Test 1999;3:37-45.

31. Tambor ES, Bernhardt BA, Chase GA, Faden RR, Geller G, Hofman KJ, Holtzman NA. Offering cystic fibrosis carrier screening to an HMO population: factors associated with utilization. Am J Hum Genet 1994;55:626-637.

32. Chase GA, Bernhardt BA, Faden RR, Geller G, Tambor ES, Holtzman NA. Confirmation of a finding on tolerance for test uncertainty (TTU) in cystic fibrosis carrier screening. Am J Hum Genet Suppl 1995;57:A29.

33. Tambor ES, Chase GA, Faden RR, Geller G, Hofman KJ, Holtzman NA. Improving response rates through incentive and follow-up: The effect on a survey of physicians' knowledge of genetics. Am J Public Health 1993;83:1599-1603.

34. Post SG, Whitehouse PJ, Binstock RH, Bird TD, Eckert SK, Farrer LA, Fleck LM, Gaines AD, Juengst ET, Karlinsky H, Miles S, Murray TH, Quaid KA, Relkin NR, Roses AD, St. George-Hyslop PH, Sachs GA, Steinbock B, Truschke EF, Zinn AB. The clinical introduction of genetic testing for Alzheimer disease. An ethical perspective. JAMA 1997;277:832-836. 